By GEORGE B. BROWN

\title{
Use of Punched Cards in Acquisition Work: Experience at Illinois
}

Mr. Brown is acquisition librarian, University of Illinois Library.

$A^{\text {ran }}$

FTER SIX MONTHS of study of various punched card systems, the University of Illinois Library at Urbana adopted Keysort cards for its acquisition records. Now that the system has been in operation for three months it is possible to make a preliminary survey of its advantages and disadvantages over the previous system.

This study of procedures was made with the hope of finding some solution to problems caused by necessary increases in salaries and the critical shortage of personnel. Mechanization of routine operations as far as possible to increase efficiency seemed to be the best answer. The adoption of the Keysort system was the result, and it is giving us the answers we want at greatly reduced costs.

The former procedure may be briefly described as follows. After the usual record searching and bibliographical identification processes were completed, a purchase order in triplicate was typed. The original copy of the purchase order was sent to the agent, the duplicate copy was filed by agent, and the triplicate copy was filed by fund. This library has over roo different funds or allocations on which books are purchased. The list price of the book was typed on the carbon copy of the purchase order and used as the figure for setting up an encumbrance against the fund on the ledger.
Then, as invoices were received and approved, the actual cost was substituted for the estimated cost on the fund copy of the purchase order. Encumbrances were lifted from the ledger in the usual manner by canceling an amount equal to the amount of the voucher. Naturally, the actual cost rarely equaled the estimated cost exactly and therefore, a reconciliation was necessary at intervals. In order to get an accurate estimate of outstanding orders, it was necessary quarterly to examine the carbon copies of all purchase orders to find out which items had not yet been received and paid for, getting a new outstanding order figure on each fund, and effecting the necessary reconciliation on the ledger. This was a time consuming process and was a bottleneck in getting bills paid.

The main disadvantages to the old system were:

(1) The process of checking off the invoices against a copy of the purchase order was time consuming and cumbersome.

(2) Considerable time was involved in filing the carbon copies of the purchase order by fund.

(3) It was not possible to have invoices paid in the usual 30-day period.

(4) No effective follow-up system on purchase orders was possible.

(5) There was no way to clear the deadwood from the outstanding orders file.

(6) There was no way to bring together all the order cards on a particular fund or all the order cards for items ordered from a particular agent. 
The McBee Company's Keysort cards seemed adaptable to procedures which would abolish these disadvantages at a reasonable cost and without disturbing the size of the file. Therefore a Keysort card was designed specifically to give us the information desired. This new order card, reproduced at right, is used as follows:

(I) An order card is made for each title to be purchased.

(2) The usual searching and verification is done and the fund and agent are stamped on the order card.

(3) The purchase order is typed and the date ordered and the purchase order number are stamped on the card.

(4) A clerk codes the card by the numerical code for author, fund, agent and date ordered. In addition, if the order is rush, the hole marked A is slotted. If the order is from a foreign country, the hole marked $B$ is slotted.

(5) The card is filed in the orders and receipts file to await receipt of the book.

(6) When the book and invoice are received the date of bill and cost are entered on the card, and the date received is stamped by the accession clerk.

(7) The field which had previously been coded for date ordered is now coded for date received.

(8) The accession clerk also slots the hole marked "Part" if the order is only partially completed or "Com" if the order is completed.

(9) The card is refiled in the orders and receipts file and remains there until the book is cataloged.

(Io) When the book has been cataloged the order card is pulled and placed in the dead file.

With this new system it is possible at any time to pull out the cards ordered on a particular fund. For that reason it is no longer necessary to go through the process of checking off the invoice against the copy of the purchase order. Now, as soon as the invoice is approved, it is entered as a disbursement in the ledger and paid.

In order to take care of the reconciliation of actual costs with estimated costs at the end of each quarter of the fiscal year, all the cards in the orders and receipts file are rearranged by fund, the items received are eliminated, and the remaining cards consist of orders which are still outstanding. In order to get the new figure of outstanding orders it is necessary only to add up the list prices from the cards on each fund and correct the ledger accordingly. At the

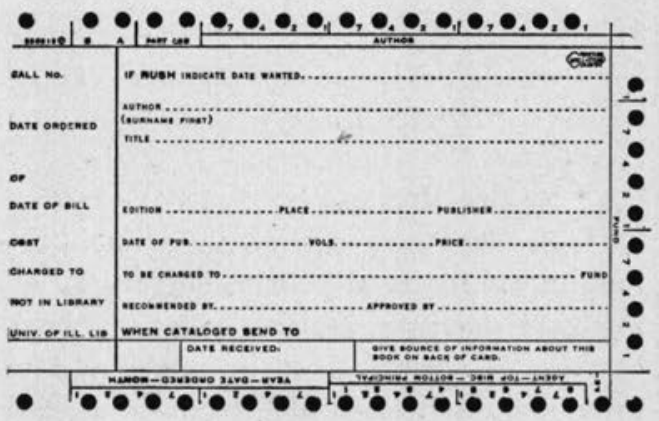

McBee Keysort Order Card

completion of that process the cards are rearranged alphabetically by using the author code.

By sorting by date ordered, it is possible to follow up orders at any desired interval. At the present time we are following up rush orders on a 30-day basis, domestic nonrush orders on a 90-day basis and foreign orders on a 6-month basis. It is very simple to drop out all the orders placed during a designated month, eliminate those which have been received and write claim letters on the remainder.

The only disadvantage to the present system, discovered so far, is that it requires the disarrangement of the orders and receipts file for approximately two days every three months. This is not considered serious.

Some figures concerning the time required in this process may be of interest. Time records were kept carefully for a three-month period. It requires an average (Continued on page 257) 
Williams, Dagny Henriette. College Library Publications as Media for Public Relations.

\section{Illinois}

Coffin, Georgia Rose. John Macock, a Seventeenth Century Printer.

Hoage, Alethia Annette Lewis. Resignations in Two University Libraries.

Knox, Margaret Enid. Publication of Scientific and Technological Research by the United States Government.

Sheppard, Edward Lee. The Radical and Labor Periodical Press in Chicago: its origin and development to 1890 .

Winger, Howard Woodrow. A Personnel Program for Student Assistants in University Libraries.

\section{Michigan}

Grondin, Francois-Zavier. Research Materials in Canadian Constitutional History and Political Science at the University of Michigan.

Manheim, Theodore. Book Publishing and Reading Interests in Philadelphia in 1802.

Phipps, Barbara. A Study of Reference Questions, in Relation to the Effectiveness of Library Instruction at Emmanuel Missionary College.

Ranz, James. The Map Library; Problems in the Development and Organization of Map Collections.

Riesner, Marianna. The Acquisition of Map Materials for a College Library.

Ulrich, John L. Guide to Postwar Wage and Salary Statistics.

\section{Use of Punched Cards}

\section{(Continued from page 220)}

of two hours per day to code the cards and file them; 15 hours every three months to arrange the cards by fund and rearrange them by author; one hour per month to follow up outstanding orders. A simple preliminary time study indicates a saving over a year's period of approximately i 8 weeks or over 700 hours of a clerk's time. The saving in salary for a six-month period will pay for a two years' supply of these cards.

In this article I have made no attempt at a detailed explanation of punched cards as such. This question was thoroughly discussed by Katherine M. Stokes in the $\mathrm{Li}$ brary Journal in 1947 and does not need repeating.

In conclusion, the following advantages of this system have become apparent:

(I) It furnishes considerable assistance in the bookkeeping operation and speeds up the processing of invoices.

(2) It offers an efficient follow-up system.

(3) After serving its primary function, the system is adaptable to various statistical studies. For example, at the end of the year for annual report purposes it will be possible to furnish statistics concerning the number of titles purchased in each subject field. Also, studies concerning the relative costs of books by subject will be possible. (It would be relatively simple to arrange the cards for all items purchased during the year by fund which is closely correlated with academic subjects, and using that figure with the amount of money spent on each fund, the average cost of books by subject could be obtained.)

(4) Filing of cards in the orders and receipts file and in the dead file becomes almost mechanical and is much faster than hand filing.

(5) By reading the slots on the cards, errors in filing and in punching show up readily.

(6) The orders and receipts file may be weeded out at regular intervals.

(7) One complete step in the processing of invoices for payment can be eliminated, thus speeding up the entire process.

(8) It will no longer be necessary to type a copy of the purchase order to be filed by fund. This will save one sheet of paper for each purchase order typed. In addition, each page of the purchase order can be filled instead of having only two or three titles per page, as a separate purchase order for each fund will not be necessary. 